\title{
The rescue of refugees:
}

a challenge for the merchant fleet

\author{
Florian Dittmann ${ }^{1}$, Martin Dirksen-Fischer ${ }^{2}$, Volker Harth ${ }^{1}$, Thomas von Münster ${ }^{1}$, \\ Stefanie Mache ${ }^{1}$, Marcus Oldenburg ${ }^{1}$ \\ 1 Institute for Occupational and Maritime Medicine Hamburg (ZfAM), University Medical Centre Hamburg-Eppendorf (UKE), Germany \\ ${ }^{2}$ Hamburg Port Health Centre, Institute for Hygiene and Environment, Germany
}

\section{INTRODUCTION}

On the $6^{\text {th }}$ of July 2015 a kick-off meeting on the topic "Rescue of refugees from distress at sea" took place at the seamen's club "Duckdalben" in Hamburg. The focus was on the challenge for the merchant shipping fleet and the stress for the seafarers caused by the rescue operations. The meeting was initiated by the Institute for Occupational and Maritime Medicine (ZfAM) and the Hamburg Port Health Centre, both facilities of the Authority for Health and Consumer Protection Hamburg, and extensively supported by the German Shipowners' Association.

The kick-off meeting was supposed to be the beginning of a professional exchange of all involved parties; therefore presentations and a panel discussion were planned. The intention was to offer support to those involved in the rescue of refugees and to work on common assisting documents and programmes. Mainly invited were representatives of German ship-owner companies to inform themselves about the current situation and bring in their experience.

At the beginning the participants were greeted by Ms. Prüfer-Storcks (Senator for Health and Customer Protection), Prof. Dr Harth (Institute for Occupational and Maritime Medicine), Dr Kröger (German Shipowners' Association) and Mr. Geitmann (ver.di). In their introductions they pointed out the current dramatic situation in the Mediterranean Sea. According to United Nations High Commissioner for Refugees (UNHCR). Europe is experiencing a refugee crisis of historical dimension with approx. 140,000 refugees at the moment arriving since the beginning of the year. While in public and political discussions the focus is on the accommodation and the care of the refugees, the current situation in the Mediterranean Sea is also an immense challenge for the merchant shipping fleet and therewith also for the seafarers. The difficulties for merchant ships in a rescue operation stem from technical reasons as well as from the small crews of these ships. The dramatic and to some extent perilous rescue operations lead to psychologically stressful events for the seafarers. Especially since the operation "Mare Nostrum" was shut down the involvement of merchant ships heavily increased. "Mare Nostrum" was an operation of the Italian navy and coast guard established in October 2013 after the drowning of approx. 400 refugees within a few days. The mission ended in October 2014, approx. 150,000 people were rescued by the operation according to the International Organisation for Migration. Subsequent to "Mare Nostrum" operation "Triton" was established in November 2014. "Triton" is an operation of the European agency Frontex originally designed for the surveillance of Italian coastal waters and parts of the Italian search and rescue area. The additional assignment of Navy Ships as well as the extension of the "Triton" mission area of operation are indeed a relief, but merchant ships are still regularly involved in rescue operations. Civil vessels ability for the rescue and adequate accommodation of the refugees are very limited and the crews are not trained for these operations. This often leads to a mismatch of the will to help and the ability to help. The experiences have to be psychologically handled by the seafarers.

\section{TOPIC OVERVIEW AND FORECAST ON A SCIENTIFIC STUDY}

The presentations started with the joint presentation of Dr Oldenburg and Dr Mache (both ZfAM). They gave a short overview on the topic of health and stress of seafarers and a forecast on a planned study with the focus on psychological stress of seafarers as a result of the rescue of refugees from distress at sea.

Doctor Oldenburg presented results from the Hamburg Seafarer Study, a study funded by the "Verkehrs-

Dr Marcus Oldenburg, Institute for Occupational and Maritime Medicine, Seewartenstrasse 10, 20459 Hamburg, Germany, tel: +49 40428374308 , fax: +49 40427313 393, e-mail: marcus.oldenburg@bgv.hamburg.de 
-Berufsgenossenschaft" that will be published next year. Aim of the study was the collection of data regarding the psychophysical stress of seafarers. Therefore, 331 seamen have been examined. A measurement of biometrical factors was conducted and psychological questionnaire was answered. In parallel to the examination, physical measurements were conducted on board of the vessels. Relevant for the topic of stress is especially the fact that the mean working hours were $9.2 \mathrm{~h}$ per day while the mean sleeping duration were $5.8 \mathrm{~h}$ per day. According to the self-evaluation of the seafarers regarding their own subjective stress, $54 \%$ of the surveyed seafarers felt stressed. The study also showed that $42 \%$ of the respondents experienced situations involving stowaways. Half of those felt stressed due to this situation. As reasons for their stress was named "Fear of potential problems with port authorities" and "Possible threat for the crew". Overall, the study showed that seafarers are remarkably psycho-mentally stressed by their daily routine. Therefore, their individual resources are already limited. This has to be considered in the context of the additional psychological stress of the seafarers caused by rescue of refugees form distress at sea.

The planned study with the topic of the rescue of refugees is designed as a survey split in two parts. The aim of the study is to describe the current situation of physical and psychological stress and deduce concrete and practical advice for the shipping companies and the seafarers. The first part of survey is addressed to the shipping companies and is used to determine the current situation from the perspective of the shipping companies. Experiences and consequences caused by the rescue operations shall be documented in this written questionnaire. From this data recommendations for the preparations of refugee relief shall be conducted and additional demand for support shall be identified.

Doctor Mache presented the second part of the planned study, a survey of the seafarers' situations. With this part of the study, the present companies' experiences with rescue of refugees shall be examined:

- which stress and strain come along with these situations;

- which apprehensions and fears do the seafarers have in this context;

- which problems are caused by these situations;

- which concrete actions and support are needed.

For this purpose it is planned to distribute questionnaires to the seafarers and conduct qualitative interviews.

\section{LEGAL ASPECTS}

An overview about the perspective of the shipping companies was given by Ms. Jörgens from the German Shipowners' Association. She presented information about the general procedures of a rescue operation and the associated legal aspects.

Miss Jörgens referred to the joint appeal of the international organisations of the shipowners and the seafarer addressed to the European administration to react on the current situation in the Mediterranean Sea. Since the operation Mare Nostrum was ended merchant vessels are increasingly involved in the rescue of refugees from distress at sea. The facts that merchant vessels are technically not suited for such operations and that the seafarers are not trained for these tasks represent a serious risk and a lot of strain for the crews. Especially the gap between the willingness of the seafarers to help and their actual possibilities lead to stressful situations. As a result of the appeal and the media documentation during the past months the first positive movements have been observed. Politicians have recognised the importance of the rescue of refugees and highlighted the priority of the topic. Additional funding was provided for the missions that are currently in place and additional navy units were committed to the sea areas. According to Ms. Jörgens these provisions should just be a beginning, the increase of the operation zone of the current missions and an enhanced commitment of the national states in the rescue from distress at sea are mandatory.

Following this introduction, Ms. Jörgens gave an overview about the organisation of rescue operations in general and the procedure of the rescue in the Mediterranean Sea in particular. According to the United Nations Convention on the Law of the Sea every coastal state is responsible for the coordination of the search and rescue services in a stipulated sea area, the Search and Rescue Region of Responsibility (SRR). For this purpose the state operates a Maritime Rescue Coordination Centre (MRCC). For the Mediterranean Sea the lead management is by the MRCC Rome. The procedures of a rescue operation are shown in Figure 1.

It is not just a moral duty for the crew to help the refugees in distress at sea, it is also a legal responsibility laid down in the rules and regulations of international shipping. The captain of a vessel is legally obligated to help in an emergency at sea. This help has to be carried out without regards to the status of the persons as asylum-seekers or the reasons for their distress, even if the distress was caused on purpose. There is no chance for merchant vessels to elude from their duty to help due to the dense network of surveillance in the Mediterranean Sea and the permanent recording of the positions, send out by the vessels. Finally Ms. Jörgens informed about the costs of such a rescue mission; the P\&I Clubs cover nearly all expenses incurred by the rescue operation. But she emphasized that the focus is not on the costs - it is on the well-being of the seafarers and the support they need to handle the challenges they are facing. 


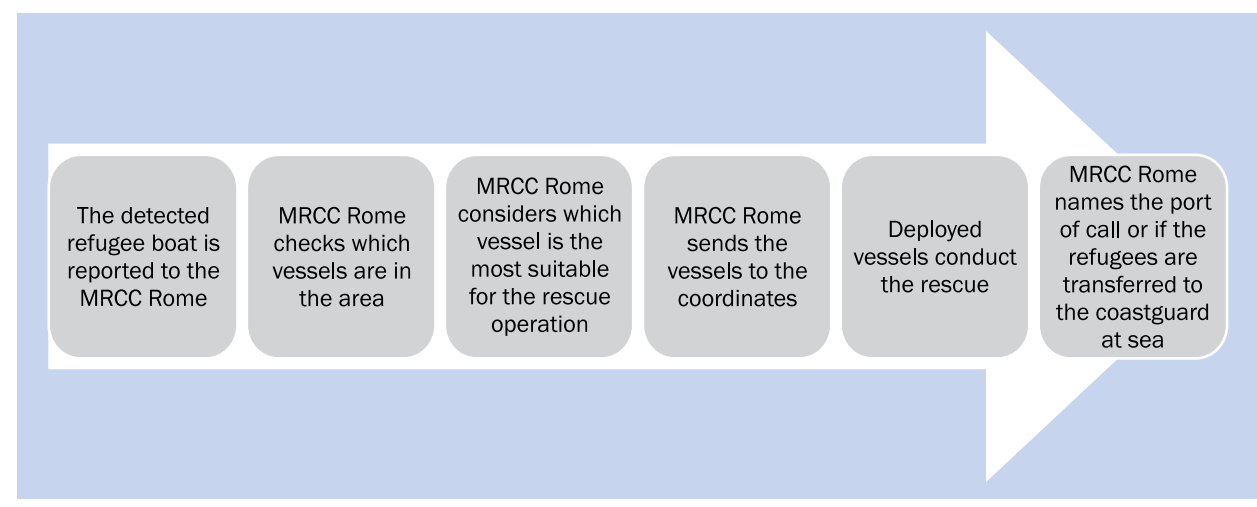

Figure 1. Processes of a rescue operation coordinated by the Maritime Rescue Coordination Centre (MRCC) Rome

\section{OPERATIONAL EXPERIENCE FROM THE GERMAN NAVY}

Surgeon Commander Dr Dr Kollenda reported on the operational experiences of the German Navy, which were gathered during the first contingent in the Mediterranean Sea.

Due to the increasing refugee crisis in the Mediterranean Sea additional vessels and money were provided by the European states for the rescue of refugees in the Mediterranean Sea. Thus, an extension of the areas of operations was possible. For the first contingent of the German Navy two vessels were committed, the frigate Hessen and the supply vessel Berlin.

In preparation for the mission detailed standard operating procedures (SOP) were developed. These SOPs should enable the crews to act in sophisticated and standardised ways. Besides the development of the SOPS additional personal was deployed: physicians, pastors, interpreters and psychologists. Additional material was also loaded on board, such as sanitary products, food and water, products for baby care, blankets, clothes, additional life-saving appliances and personal protection equipment for the crew.

Afterwards the vessels were prepared for the operation. Therefore, the following arrangements were made: on the flight deck an area for the rescued was set up, an area for the treatment of sick or injured was separated as well as washing facilities and toilets installed on the flight deck. For the toilets plastic-booths with chemical-toilets were used. Due to this layout it could be avoided to bring the rescued inside the ship. To rescue the refugees from the water or from their boats two life rafts were prepared; the covers of these life rafts were removed to make the boarding and deboarding easier. Besides these preparations the crew was informed about the circumstances of the mission for example about the danger of infections like scabies, varicella and tuberculosis.

The ships were deployed by the MRCC Rome. After the alert by the MRCC the crew usually had about $2 \mathrm{~h}$ to reach the location of the refugee boat. This time was used to prepare the wards, to brief the crew for the upcoming rescue operation, to check and to put on the protection equipment.

After reaching the refugee boat, all operations followed the same schedule. First contact was made by Arabic and French speaking interpreters, the refugees were informed about the procedures of the rescue and necessary information was gathered. Afterwards the refugees were shuttled by two speed boats to the vessel. There they were transferred to the open-top life rafts and then onto the ship. On board, a brief security check was conducted immediately followed by a brief medical check to identify acutely sick or injured people. All refugees were registered to a number and a corresponding list was prepared. Additional lists were generated for women, pregnant women and children. After the registration everybody was supplied with a blanket, bread and a bottle of water. Medical treatment was conducted if it was demanded or if anybody showed signs for acute sickness. All medical treatments were documented. The rescued refugees were transferred to a vessel of the coastguard or a port after a maximum of $24 \mathrm{~h}$. There were no problems during the transportation.

Due to the brief stay on board the ship the additional stored sanitary products were barely needed. Not many of the refugee boats were in urgent distress but they would have been in the immediate future. Dr Dr Kollenda reported that many of the boats deliberately called for help at an early stage. Due to the sufficient availability of personnel and equipment on board precise and effective rescue operations were possible.

\section{ASPECTS OF INFECTION CONTROL HYGIENE AND RISK OF INFECTION}

Doctor Plenge-Bönig from the Institute of Hygiene and Environment, a facility of the Authority for Health and Consumer Protection Hamburg, gave a presentation on the expectable risk of infectious diseases and epidemics as well as on the provisions to be protected against these.

The general risk to be confronted with well-known epidemics like Ebola, plague or cholera is low, due to the fact 
that they are not common in the provenance of the refugees and that these diseases can lead to such severe disorders that the sick would not be transportable. Also the transmission of classical tropical diseases like malaria, yellow fever or dengue fever should not be expected because they are transmitted by vectors, for example by mosquitos, and not transmitted from person-to-person. However, it is possible that individual refugees can be affected by those diseases.

Health symptoms that should be expected among refugees are dehydration, mental and physical exhaustion and acute infectious diseases. Beside these symptoms injuries, sunburn respectively sunstroke, seawater intoxication, and advanced pregnant women should be expected. Severe acute infections will be often recognised because they usually come along with fever. Tuberculosis on the other hand can be problematic to diagnose.

Based on a survey about refugees who fled overland via Slovakia to Europe, an overview on the occurrence of common diseases in these people was presented. Among these refugees the following diseases occurred:

- diseases of the upper respiratory tract;

- pneumonia;

- skin diseases (ulceration of the skin, scabies, other ectoparasites);

- gastro-intestinal diseases;

- intestinal parasites;

- tuberculosis (small number).

In addition to the expected diseases possible and required safety precautions were discussed (Table 1). It was pointed out that sanitary measures offer protection against most of the infectious diseases, particularly essential for the protection are masks (class FFP3), safety goggles, protective clothing and gloves. It is important to plan the disposal of the used and maybe contaminated protection equipment. If possible the rescued should be separated from the crew and the sick should be separated from the healthy. The sanitation areas should be separated from each other in particular and everybody should be encouraged to practice general hygiene.

The occurrence of vermin, like lice, fleas or bedbugs cannot be excluded, but there is only a low risk for disease transmission, although some cases of lice relapsing fever were recently reported among refugees (transmission by clothes lice). The spread can be avoided by using protective measures and the clothing affected by clothes lice should be disposed and exchanged.

In addition to the safety precautions, all rescued people should be registered and occurring diseases should be documented. The medical logbook should be carefully and continuously administrated. The state of health of the crew should be observed even after the transfer of the refugees to recognise any infection as early as possible. Company physicians should be informed.

A distinctly more detailed overview of possible infectious diseases was published in the "Epidemiologisches Bulletin" of the Robert Koch Institute: http://www.rki.de/DE/Content/ Infekt/EpidBull/Archiv/2015/Ausgaben/38_15.pdf;jsessionid=2B605D624BDB4A583D271F167698126D.2_ cid290?_blob=publicationFile.

Preliminaries for the protection of the crew from infections are securing a complete immunisation protection, providing protective clothing, protective equipment and disinfectants and informing the crew about the expected hazards. Company physicians should be included also in this process.

\section{ASPECTS OF PSYCHOSOCIAL EMERGENCY CARE}

Information about psychosocial emergency care was presented by Prof. Dr Jensen, former professor of the University of Applied Sciences Flensburg and an expert in the field of maritime psychology.

The purpose of psychosocial emergency care is to support coping potential traumatic experiences. It is no

Table 1. A selection of infectious diseases and provisions

\begin{tabular}{|c|c|c|}
\hline Infectious disease & $\begin{array}{l}\text { Contagious- } \\
\text { ness (without } \\
\text { provisions) }\end{array}$ & Provisions for the crew \\
\hline Diarrhoea (viral, bacterial, parasitical), hepatitis A and E & ++ & Hygiene, separated sanitation, disinfection \\
\hline Acute respiratory diseases (viral, seasonal influenza) & +++ & Mask (mouth and nose), protective clothing \\
\hline Scabies & ++ & Protective clothing, avoid contact with the skin \\
\hline $\begin{array}{l}\text { Measles, mumps, varicella (viral) (so called children's } \\
\text { diseases, if not vaccinated also in adults) }\end{array}$ & +++ & $\begin{array}{l}\text { Mask (mouth and nose), protective clothing, with varicella, } \\
\text { avoid contact with the skin (fluid of the blisters is contagious) }\end{array}$ \\
\hline Whooping cough & +++ & Mask (mouth and nose), protective clothing \\
\hline Meningitis (bacterial) & + & Mask (mouth and nose), contagious only in close contact \\
\hline Tuberculosis & ++ & Mask (mouth and nose), protective clothing \\
\hline Dengue fever, malaria, leishmaniosis (need vector) & None & \\
\hline
\end{tabular}


psychotherapy, but can be applied to avoid the development of a posttraumatic stress disorder. Potential traumatic experiences during a refugee rescue operation can be the confrontation with an apparently insolvable challenge, screams and cries for help, seeing injured or dead bodies and especially injured and dead children.

The symptoms of a trauma can manifest immediately or with a delay of several months or even years. The following symptoms are common for trauma:

- oppressive and stressful thoughts and memories of the incident;

- symptoms of overexcitation, like sleep disorder or concentration impairments;

- avoidance behaviour;

- emotional numbness.

Not all of these symptoms have to be present; an isolated occurrence or a combination of only a few of them is also possible.

According to Prof. Dr Jensen, specific problems in the psychosocial emergency care for ship crews are due to the working environment and the structure. Usually the crews are on their own and do not have the chance to make use of external help on short notice. The subjective perception of the incident is very different due to the different social and cultural background of the crew members. For seafarers it is sometimes hard to communicate that they are in need of support. Fear, embarrassment and anger are often introversive, which can lead to problems in the examination with the experiences, emotions and physical reactions.

During the psychosocial care certain principles have to be respected - first of all, critical incidents are experienced differently. Therefore, a readiness for a dialog should be signalised without forcing someone to talk. A faithful relationship has to be created to make it possible for the affected crew member to talk about the experience. If possible he should be shielded from the environment to grant him safety. Conversations should always be conducted in an undisturbed setting. Rituals can be a way into conversations. A lot of the seafarers are religious and looking for relief in joint prayers. The conversation and asking-technique should be very careful. Described experiences and emotions should not be judged. It can be relieving for the affected person to know that the psychological and physical symptoms are normal reactions after a traumatic experience. It can be important for the acute helper to distance himself from the experiences and emotions of the affected person and do not identify with them. The integration within a group, religion, orientation towards a person of confidence and family relationships are important psychological resources to cope with a trauma. Posttraumatic stress disorders can lead to psychosomatic symptoms, substance abuse and depressive moods.
According to Prof. Dr Jensen, psychosocial emergency care is conducted among others by crisis intervention teams, educated peers from the same occupational group as the affected person, emergency psychologists and emergency pastoral support. It is important for shipping companies to develop an assistance concept for their seafarers, build up a network with the existing facilities and institutions and inform the seafarers about consulting and assisting options. Especially in the seamen's mission Prof. Dr Jensen sees a competent partner due to the existing familiar initial contacts and the fact that they are offering a safe environment far from the ship and pastoral support.

Information for the affected seafarers should be available in multiple languages (possibly the native language). It should point out the common reactions, physical and mental. In addition they could contain behavioural rules, easy to follow instructions and information about consulting and assisting options.

\section{ASPECTS OF PASTORAL CARE}

Pastor Proske, General Secretary of the German Seamen's Mission, dedicated her presentation to the pastoral aspects of the refugee relief and delivered insight into her experiences with affected seamen.

She talked about the daily routine of the seamen's mission in which seafarers are looking for a person to which they can talk faithfully about their experiences. She also talked about the relatives of the affected seafarers who worry about the affected because they are showing signs of stress or are acting "strange". At this point, the pastoral care is of big importance and should be normal together with psychosomatic and psychotherapeutic support, unfortunately that is not always the case. Moreover, the affected seafarers often fear negative consequences if they enlists for someone's assistance. Thus, mental or emotional problems are not or just rarely addressed towards the employer.

Miss Proske described that she hears more and more reports about experiences with refugees from the seafarers and that it is hard for some of them to know that their next charter is going to the Mediterranean Sea. They often open up to the staff of the seamen's mission because they know that they have neutral contact persons in them. According to Ms. Proske, this is one of the advantages of the seamen's missions. There often is a familiarity with the seamen's mission from visits to the clubs or visits to the ships. Even if the ship visitor or the staff of the club is not known personally there is a general bond of trust. The seafarers know that the seamen's mission is a resilient partner in crisis situation to whom they can turn to with their worries and fears.

Often, it is not the direct response to the worries and needs of the seafarers, but rather to look out for the little 
hints which have to be recognised and addressed in one-toone interviews to offer help. The seafarers need the distance to the ship and its hierarchy. They often don't realise that there is something they have to talk about, but open up as a result of the conversation. This is where the staff of the seamen's mission often faces their limits. Some of the stations do not have enough personnel to take time to talk to the affected seafarers in detail. Another limitation is the language for the seafarers; it is difficult to describe their emotional situation in a language that is not their native language and for the seamen's mission's staff it is difficult to read between the lines and recognise the essential nuances.

Besides their direct pastoral work, the seamen's mission can also assist with help. All full-time employees are trained in psychosocial emergency care. They can also explain to the seafarers that their reactions and emotions are absolutely normal and refer them to people or organisations which can offer help if needed.

\section{PANEL DISCUSSION}

Following the presentations it was up to the participants to ask the speakers their questions or discuss them with the audience. This opportunity was well used and resulted in a brisk discourse. The following passages give a summary of the different topics brought up in the panel discussion.

The audience agreed on the opinion that the rescue of refugees from distress at sea is a governmental duty in the first place. Vessels of the merchant fleet are willing to make their contribution to the rescue mission but neither the ships nor the crews are suitable for this task. The navy vessels, operating in the Mediterranean Sea at the moment, are a relief for the merchant vessels. A further expansion of the operation areas and an enduring engagement would be desirable.

Another topic of the discussion was the preparation and additional equipment for ships. Here, standard operating procedures were named as a highly appropriate instrument. A lot of the participants regarded them as a possibility to be prepared for the technical and organisational part of the rescue operation. Therefore, the exchange of information of all participants should be promoted to minimise the effort for the individual, should build up from existing procedures and use the experiences and lessons-learned from others.

Providing additional equipment, especially safety equipment (overalls, masks, goggles and gloves) was discussed as well. One question was if the crew's fears of infections are promoted by these provisions particularly with regard to the fact that the risk of severe infections is extremely low. In spite of the low probability to be infected with a serious disease comprehensive protection and sanitary provisions are nevertheless reasonable to reduce the negative consequences for the crew as far as possible. A comprehensive protection from infections, even from the minor severe disease, is necessary because the protection from infection should be preferred to the treatment. Furthermore the risk of a tuberculosis infection is given and the crew has to be protected from it. Besides the protective use of the equipment there can also be a positive psychological effect on the crew. The information of the seafarers regarding the risk of infectious diseases and their familiarity with the procedures and the use of the equipment are essential.

The reduction of communication barriers was another topic of the discussion. It is important to inform the refugees about the upcoming rescue. They have to know that they will be rescued and that it is not planned to send them directly back to their countries of origin. This can help to avoid panic on the refugee boats or dangerous situations of refugees or potential facilitators trying to force the captain to change the course. The assignment of translators is impossible for the merchant shipping companies. Prepared messages on signs or recorded information in different languages can be a low-threshold solution.

Besides all of the mentioned technical and organisational aspects of the rescue all participants agreed on the importance of assisting services for the seafarers. These services should be promoted and the seafarers should be informed about them. The focus should be on the information about possible reactions to stressful incidents and potential contacts and facilities offering help. Thereby the acceptance of psychosomatic reactions and the need for help can be supported. This information has to be accessible to the seafarers in an understandable language and in writing.

\section{CONCLUSIONS}

This first meeting showed a need from the shipping companies as well as from the involved organisations to exchange information and experiences. It became clear that the networking of all involved parties is of great importance - with the intention to exchange lessons-learned and develop joint action strategies. Besides the already existing experiences and findings new and still open questions have to be discussed and answered. The participants argued for continuing this meeting in future to define interfaces of scientific knowledge (for example from the planned questionnaire-study) and the practical use for the shipping companies and the involved organisations.

\section{CONFLICT OF INTEREST AND AUTHOR'S CONTRIBUTION}

The authors did not receive any grants or financial support for this manuscript.

Florian Dittmann wrote the article and all authors gave substantial contributions to the preparation and content of the text. All authors have read and approved the final manuscript. 